\title{
PENGARUH PERILAKU AGRESIF PADA ANAK USIA DINI TERHADAP KECEMASAN DAN EMPATI
}

\author{
Fifi Khoirul Fitriyah \\ Universitas Nahdlatul Ulama Surabaya \\ Email: fifi@unusa.ac.id
}

\begin{abstract}
Abstrak: Perilaku agresif merupakan masalah serius yang terjadi bukan hanya di Indonesia, melainkan juga menjadi perhatian dunia. Tujuan penelitian ini adalah untuk mengetahui hubungan antara perilaku agresif terhadap kecemasan dan empati pada anak usia dini di Kota Surabaya. Pendekatan penelitian adalah kuantitatif dengan metode korelasi. Hasil penelitian menunjukkan adanya korekasi yang signifikan antara perilaku agresif pada anak usia dini terhadap kecemasan dan empati. Rekomendasi untuk peneliti selanjutnya adalah agar mencari solusi atas perilaku agresif yang terjadi khususnya pada anak-anak.
\end{abstract}

Kata Kunci: Agresif, Anak-anak, Empati, dan Kecemasan.

\begin{abstract}
Aggressive problems are a serious problem that occurs not only in Indonesia, but also concerns the world. The purpose of this study was to study the relationship between aggressive behaviour in early childhood in Surabaya toward anxiety and empathy. Research approval is quantitative with correlational methods. The results of the study showed a significant correlation between aggressive behavior in early childhood towards anxiety and empathy. The recommendation for further research is to find solutions to the aggressive problems that occur in children.
\end{abstract}

Keywords: Aggression, Children, Empathy, and Anxiety.

\section{PENDAhUluan}

Perilaku agresif merupakan masalah serius yang dialami individu baik bagi kehidupan pribadi maupun sosial, dan telah menjadi masalah serius baik di Indonesia maupun di skala internasional. Indonesia bahkan belakangan ini mendeklarasikan "darurat kekerasan anak" akibat banyaknya kasus kekerasan yang terjadi pada anak-anak. Mirisnya banyak kasus kekerasan tersebut dilakukan oleh antar anak-anak sendiri dan terjadi di lingkungan sekolah (KPAI.go.id, 14 Juni 2015).
Kejadian perilaku agresif pada anakanak di Indonesia meningkat sekitar 1000 kasus setiap tahunnya. Pada tahun 2011 terjadi sebanyak 2178 kasus, 2012 ada 3512 kasus, 2013 ada 4311 kasus, dan 2014 ada 5066 kasus. 78,3\% dari kasuskasus tersebut pelakunya adalah anakanak sendiri, dan $87,6 \%$ kasus terjadi di lingkungan sekolah (KPAI.go.id, Juni 2015). Dampak agresi pada anak-anak bukan hanya menyebabkan luka fisik melainkan juga luka psikis. 
Perilaku agresif memiliki hubungan positif terhadap masalah-masalah psikologis lainnya yakni gangguan kepribadian narsistik (Ojanen, et al., 2012; Vaillancourt, 2013; Ghim, et al., 2015, Fitriyah \& Purwoko, 2018), kenakalan remaja dan depresi (Tucker, et al., 2014), depresi (Blain-Arcaro, 2016), kecemburuan (Wright, 2014), rendahnya empati (van Hazebroek, 2016), selfcontrol yang rendah (Morsunmbul, 2015; Guo, et al., 2016), self-injury (Tang, et al., 2013), self-perception (Wallance et al, 2012), depresi dan stress (Esteves, 2018). Banyaknya masalah psikologis yang erat dengan perilaku agresif merupakan sinyal bahwa perilaku agresif merupakan masalah utama yang berdampak sistemik pada kondisi psikologis manusia.

Di Amerika Latin, khususnya Mexiko mengakui bahwa dunia pendidikan telah dilanda masalah serius ini, namun hingga kini masih sedikit penelitian yang membahasnya (Jimenez \& Estevenes, 2017). Bukan hanya di Amerika Latin, bahkan di Indonesia juga mengalami permasalahan yang sama. Sehingga penting adanya penelitian yang mengkaji tentang perilaku agresif sejak dini yakni pada anak-anak dan mengetahui kaitan-kaitan perilaku agresif terhadap masalah psikologis lainnya, dalam penelitian ini difokuskan pada empati dan kecemasan.

\section{TINJAUAN PUSTAKA}

Seorang ilmuwan yang fokus dibidang perilaku manusia Arnold $\mathrm{H}$. Buss dalam bukunya "The Psychology of Aggression" tahun 1961 menjelaskan perilaku agresif pada manusia secara rinci. Buss (1961: 1) menyatakan perilaku agresif adalah perilaku yang membahayakan orang lain. Geen (2001: 1-3) dalam bukunya "Human Aggression" menjelaskan definisi perilaku agresif bukan hanya pada seputar perilaku yang tampak saja. Namun terdapat beberapa unsur yang mendasari perilaku yang tampak, yakni: niat untuk membahayakan (intent to harm), motivasi dari korban (motivation of the victim), definisi agresi (a definition of aggression), dan bentuk agresi (the form of aggression).

Beberapa psikolog mendefinisikan agresi sebagai perilaku yang menyebabkan cidera, rasa sakit, dan luka disebabkan kemarahan (Dollard dalam Buss, 1961: 2). Geen (2001: 2) menyatakan bahwa perilaku agresif didasari oleh niat untuk menyakiti orang lain yang bertujuan membuat orang lain terluka. Perilaku agresif merupakan hasil akhir dari serangkaian tindakan yang disengaja. Pendapat sama disampaikan oleh Baron dan Richardson (Geen, 2001: 2), perilaku agresif adalah bentuk perilaku yang bertujuan menyakiti atau melukai hidup orang lain yang dianggap berbahaya hidupnya. Pelaku perilaku agresif berusaha menyelamatkan dirinya agar tidak menjadi korban oleh orang lain dengan cara menyakiti orang tersebut.

Buss (1961: 1) mendeskripsikan perilaku agresif menggunakan tiga istilah yakni; instrumental, emosi, dan sikap. Perilaku instrumental digambarkan dalam bentuk agresi fisik dan verbal, perilaku emosi digambarkan dalam bentuk perilaku marah, dan sikap digambarkan dalam perilaku permusuhan. Istilah lain yang mirip dengan istilah Buss dalam mendeskripsikan perilaku dijelaskan oleh 
Ana et al., (2002), ketiga istilah tersebut yakni perilaku, afeksi, dan kognitif. Ketiga istilah tersebut merupakan aspekaspek yang memiliki keterkaitan yang erat. Aspek perilaku digambarkan dengan agresi fisik dan verbal, aspek afeksi digambarkan dengan perilaku kemarahan, dan aspek kognitif digambarkan dengan perilaku permusuhan.

\section{METODE PENELITIAN}

Pendekatan penelitian yang digunakan dalam penelitian ini adalah kuantitatif. Cresswell (2012) menyatakan pendekatan kuantitatif dipilih sebagai pendekatan penelitian ketika tujuan penelitian adalah sebagai berikut; menguji teori, mengungkapkan faktafakta, menunjukkan hubungan antar variabel, dan memberikan deskripsi statistik. Tujuan penelitian ini adalah untuk hubungan antar variable yakni perilaku agresif, kecemasan, dan empati.

Penelitian ini melibatkan 118 anak usia dini di Kota Surabaya. Teknik pengambilan sampel dilakukan dengan teknik random sampling. Instrumen penelitian menggunakan tiga angket yakni: Buss and Perry Agression Questionnaire (BPAQ), Child Anxiety Related Disorder (SCARED), dan Empathy Questionnaire (EmQue). Ketiga instrument tersebut telah dikonversi kedalam Bahasa Indonesia dan telah dinyatakan valid. Reliabilitas masingmasing instrument sebagai berikut: $\mathrm{BPAQ}=0.81, \mathrm{SCARED}=0.76$, dan EmQue=0.79. Dengan hasil tersebut, dapat disimpulkan bahwa ketiga instrument telah layak digunakan dalam penelitian.

\section{HASIL PENELITIAN DAN PEMBAHASAN}

Tujuan penelitian ini adalah untuk mengugi hubungan antara perilaku agresif terhadap kecemasan dan empati pada anak usia dini di Kota Surabaya. Berdasarkan tabel output di atas diketahui nilai Sig. (2-tailed) antara perilaku agresif dengan kecemasan adalah sebesar $0.00>$ 0.05 yang berarti terdapat korelasi yang signifikan antara variable perilaku agresif dan kecemasan. Selanjutnya hubungan antara perilaku agresif dan empati memiliki nilai Sig. (2-tailed) sebesar 0.04 $<0.05$, sehingga juga dapat dinyatakan bahwa ada korelasi yang kuat antara variable perilaku agresif dan empati.

Tabel 1 Hasil Uji Korelasi

\begin{tabular}{|c|c|c|c|c|}
\hline \multicolumn{2}{|c|}{ Correlations } & Agresi & Kecemasan & Empati \\
\hline \multirow{3}{*}{ Agresi } & $\begin{array}{l}\text { Pearson } \\
\text { Correlati } \\
\text { on }\end{array}$ & 1 & $.355^{* *}$ & .073 \\
\hline & $\begin{array}{l}\text { Sig. (2- } \\
\text { tailed) } \\
\end{array}$ & & .000 & .435 \\
\hline & $N$ & 118 & 118 & 118 \\
\hline \multirow{3}{*}{$\begin{array}{l}\text { Kecem } \\
\text { asan }\end{array}$} & $\begin{array}{l}\text { Pearson } \\
\text { Correlati } \\
\text { on } \\
\end{array}$ & $.355^{* \star}$ & 1 & $.265^{\star *}$ \\
\hline & \begin{tabular}{|l|} 
Sig. $(2-$ \\
tailed) \\
\end{tabular} & .000 & & .004 \\
\hline & $N$ & 118 & 118 & 118 \\
\hline \multirow{3}{*}{ Empati } & $\begin{array}{l}\text { Pearson } \\
\text { Correlati } \\
\text { on } \\
\end{array}$ & .073 & $.265^{\star *}$ & 1 \\
\hline & $\begin{array}{l}\text { Sig. }(2- \\
\text { tailed) } \\
\end{array}$ & .435 & .004 & \\
\hline & $N$ & 118 & 118 & 118 \\
\hline
\end{tabular}

${ }^{* *}$. Correlation is significant at the 0.01 level (2-tailed).

Perilaku agresif pada anak-anak sebenarnya merupakan sesuatu yang normal terjadi, namun dampak yang timbul setelahnya sangat membahayakan. Selain perilaku agresif, kecemasan juga umum terjadi pada anak-anak. Trivedi 
dan Gupta (2010) mendefinisikan kecemasan adalah emosi manusia normal yang melibatkan respon perilaku, afektif, dan kognitif terhadap adanya bahaya. Namun pada kasus kecemasan, respon yang muncul dianggap berlebihan atau tidak sebanding dengan tantangan atau stress yang sedang dihadapi. Tentu hal ini diprediksi berpengaruh terhadap perilaku agresif.

Krain, et al. (2007) memandang kecemasan pada anak-anak sebagai bagian yang normal terjadi dari masa anak-anak. Anak-anak mudah sekali mengalami ketakutan, kegugupan, malu, dan penghindaran. Prevalensi gangguan kecemasan berkisar antara 4\% - 20\% puplasi. Costello, et al., (2004) menyatakan gangguan kecemasan umum pada anak-anak adalah fobia spesifik, fobia sosial, kecemasan umum, dan kecemasan pemisahan yang memiliki prevalensi antara $2.2 \%-3,6 \%$. Meski gejala-gejala kecemasan sepertinya sangat dekat dengan gejala perilaku agresif, namun hasil penelitian menunjukkan tidak adanya hubungan yang signifikan antara kedua variable tersebut.

Meskipun tidak sebesar kecemasan pengaruhnya terhadap pembentukan perilaku agresif, namun empati juga memiliki peran terhadap perilaku agresif pada anak-anak. Empati merupakan sebuah kondisi emosi yang disebabkan karena kondisi emosi orang lain. Orang mampu merasakan tentang apa yang dirasakan orang lain pada situasi tertentu (Hoffman, 2008). Empati cenderung menekankan pada kemampuan seseorang dalam merespon orang lain berdasarkan pertimbangan kognitif dan afektif (Garaigordobil, 2009).

Howe (2015) menyatakan bahwa anak-anak yang terlibat dalam perilaku agresif diakibatkan karena memiliki kualitas empati yang rendah. Kualitas pengasuhan orangtua sangat berdampak pada perkembangan empati pada anakanak. Pada kasus-kasus perilaku agresif, hasil-hasil penelitian menunjukkan bahwa individu yang terlibat dalam pola agresif memiliki kemampuan akademik rendah (Roman dan Murillo, 2011; Kowalski dan Limber, 2013). Kapasitas intelektual yang rendah berdampak pada ketidakmampuan mengembangkan empati, sehingga seseorang tidak mampu merasakan tentang apa yang dirasakan oleh orang lain. Komponen afektif sangat erat kaitannya dengan empati (Mercer dan Clayton, 2012).

Dalam membentuk kemampuan empati pada anak-anak, Howe (2015) merekomendasikan pendekatan keluarga dan sekolah. Orangtua dan guru dapat membantu anak-anak mengenali, memahami, dan mendiskusikan emosi diri sendiri dan orang lain, serta memberi pengertian pada anak tentang bagaimana cara memahami keadaan dan pengalaman orang lain. Sroufe (Howe, 2015) menjelaskan bahwa anak-anak akan menjadi lebih empati jika ia mendapatkan perlakuan empati dari orang lain khususnya orangtuanya.

Pendekatan sekolah akan mendukung pengembangan empati pada anak-anak karena melibatkan hubungan dengan teman sebaya. Anak-anak akan memiliki kesempatan untuk berbicara, berkomunikasi, memahami orang lain, bermain bersama, berimajinasi, berbagi, 
bergiliran, mengendalikan kemarahan dan ketidaksabaran, memecahkan konflik dan mengatasi problem sosial dalam mengambil sebuah keputusan dengan teman sebayanya (Howe, 2015).

Penelitian terdahulu juga merekomendasikan konsep dalam penanganan perilaku agresif yakni dengan mengatasi frustrasi dan membangun perilaku konstruktif dalam menghadapi bahaya (Fitriyah, 2017). Dalam hal ini peran sekolah diperlukan untuk mendukung terbentuknya sebuah program pendidikan damai dalam mencegah agresif dengan memanfaatkan variabel-variabel kunci sebagai komponen-komponen dalam merumuskan intervensi.

\section{SIMPULAN DAN SARAN}

Perilaku agresif memiliki kaitan yang erat dengan kecemasan dan empati. Perilaku agresif dan kecemasan merupakan masalah psikologis yang normal terjadi pada anak-anak, keduanya memiliki kaitan yang sangat erat, begitupula empati. Ketika seseorang memiliki empati tinggi maka perilaku agresifnya rendah, sehingga empati merupakan salah satu variable kunci dalam merumuskan solusi atas permasalahan perilaku agresif pada anakanak.

Adapun saran untuk peneliti selanjutnya adalah: (1) Perlu adanya penelitian yang menggali faktor-faktor budaya lokal yang berpengaruh pada perilaku agresif anak-anak, dan (2) Penting adanya program pencegahan perilaku agresif pada anak-anak di sekolah.

\section{DAFTAR PUSTAKA}

Blain-Arcaro, C., \& Vaillancourt, T. (2016). Does worry moderate the relation between aggression and depression in adolescent girls? Journal of Adolescence, 49, 10-18. https://doi.org/10.1016/j.adolesc ence.2016.02.006.

Buss, Arnold H. (1961). The Psychology of Aggression. New York and London: John Wiley and Sons, Inc.

Costello EJ, Egger HL, Angold A. 2004. Developmental epidemiology of anxiety disorders In Ollendick TH, March JS, editors Phobic and anxiety disorders in children and adolescents $A$ clinician's guide to effective psychosocial and pharmacological interventions. New York: Oxford University Press; 2004.; pp. 61-91.

Estévez, E., Jiménez, T. I., \& Moreno, D. (2018). Aggressive behavior in adolescence as a predictor of personal , family , and school adjustment problems, 30(1), 66-73.

https://doi.org/10.7334/psicothe ma2016.294.

Fitriyah, Fifi Khoirul. (2017). Reducing Aggressive Behaviour using Solution Focused Brief Counseling. JBKI (Jurnal Bimbingan Konseling Indonesia) 2 (2), 34-39, DOI: http://dx.doi.org/10.26737/jbki. $\mathrm{v} 2 \mathrm{i} 2.254$.

Fitriyah, Fifi Khoirul., dan Purwoko, Budi. (2018) Youth Narcissistic and Aggression: A Challenge for Guidance and Counseling Service in University. 1st International Conference on 
Education Innovation (ICEI 2017).

Garaigordobil, M. (2009). A

Comparative Analysis of

Empathy in Childhood and

Adolescence: Gender

Differences and Associated

Socio-emotional Variables.

International Journal of

Psychology and Psychological

Therapy. 09(2), 217-235.

Geen, Russell G. (2001). Human

Aggression. Buckingham: Open

University Press.

Ghim, S. C., Choi, D. H., Lim, J. J., \&

Lim, S. M. (2015). The

Relationship between Covert

Narcissism and Relational

Aggression in Adolescents:

Mediating Effects of

Internalized Shame and Anger

Rumination. International

Journal of Information and

Education Technology, 5(1),

21-26.

https://doi.org/10.7763/IJIET.20 15.V5.469

Guo X., Egan V., \& Zhang J. 2016.

Sense of control and

adolescents' aggression: The

role of aggressive cues. Psych J.

2016 Dec;5(4):263-274. doi:

10.1002/pchj.151.

Howe, David. (2015). Empati : Makna

dan Pentingya. Yogyakarta :

Pustaka Belajar

Hoffman, M. (2008). Empathy And

Prosocial Behaviour, dalam

Handbook Of Emotions-Second

Edition, Edited By Michael

Lewis And Jeannette M.

Haviland-Jones. New York :

The Guilford Press.

Krain AL, Ghaffari M, Freeman J,

Garcia A, Leonard H, Pine DS.

(2007). Anxiety disorders.
Lewis's child and adolescent

Psychiatry. In: Martin A,

Volkmar FR, editors. 4th ed.

Philadelphia: Lippincott

Williams and Wilkins; 2007. pp.

538-48.

Mercer, J \& Clayton D. (2012).

Psikologi Sosial. Erlangga :

Jakarta.

Morsünbül, Ü. (2015). The Effect of Identity Development, SelfEsteem, Low Self-Control and Gender on Aggression in Adolescence and Emerging Adulthood. Eurasian Journal of Educational Research, 15(61), 99-116.

https://doi.org/10.14689/ejer.20 15.61 .6

Ojanen, Tiina., Danielle Findley., dan Sarah Fuller. (2012). Physical and Relational Aggression in Early Adolescence:

Associations with Narcissism, Temperament, and Social Goals. Aggressive Behavior Volume 38 Issue 2 March/April 2012 Pages 99-107 DOI: 10.1002/ab.21413.

Rieffe, C., Ketelaar, L., \& Wiefferink, C.H. (2010). Assessing empathy in young children; construction and validation of an empathy questionnaire (EmQue). Personality and Individual Differences, 49, 362-367.

Trivedi, JK., \& Gupta PK. (2010). An overview of Indian research in anxiety disorders. Indian $J$ Psychiatry. 2010;52 (Suppl 1):S210-8.

Tang, J., Ma, Y., Guo, Y., Ahmed, N. I., Yu, Y., \& Wang, J. (2013).

Association of aggression and non-suicidal self injury: a 
school-based sample of adolescents. PloS One, 8(10).

https://doi.org/10.1371/journal. pone.0078149.

Tucker, C. J., Van Gundy, K. T., Wiesen-Martin, D., Hiley Sharp, E., Rebellon, C. J., \& Stracuzzi, N. F. (2015).

Proactive and Reactive Sibling Aggression and Adjustment in Adolescence. Journal of Interpersonal Violence, 30(6), 965-987.

https://doi.org/10.1177/0886260 514539760

Vaillancourt, Tracy. (2013). Students Aggress Against Professors in Reaction to Receiving Poor Grades: An Effect Moderated by Student Narcissism and Self-

Issue 3 May-June 2012 Pages 213-221 DOI: 10.1002/ab.21419.

Wright, M. F. (2014). Cyber Aggression Within Adolescents' Romantic Relationships: Linkages to
Esteem. Aggressive Behavior Volume 39 Issue 1 Januari 2013 Pages 71-84 DOI: 10.1002/ab.21450.

Van Hazebroek, B. C. M., Olthof, T., \& Goossens, F. A. (2017). Predicting aggression in adolescence: The interrelation between (a lack of) empathy and social goals. Aggressive Behavior, 43(2), 204-214. https://doi.org/10.1002/ab.2167 5

Wallace, Marion T., et. al. (2012). Locus of Control as a Contributing Factor in the Relation Between Self-Perception and Adolescent Aggression. Aggressive Behavior Volume 38

Parental and Partner Attachment. Journal of Youth and Adolescence, 44(1), 37-47. https://doi.org/10.1007/s10964014-0147-2 